GLOBAL WATER PATHOGEN PROJECT

PART THREE. SPECIFIC EXCRETED PATHOGENS: ENVIRONMENTAL AND EPIDEMIOLOGY ASPECTS

\title{
SUMMARY OF EXCRETED AND WATERBORNE VIRUSES
}

\author{
Marta Rusiñol \\ University of Barcelona
}

Rosina Girones

University of Barcelona

Barcelona, Spain 


\section{Copyright:}

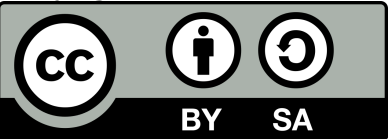

This publication is available in Open Access under the Attribution-ShareAlike 3.0 IGO (CC-BY-SA 3.0 IGO) license (http://creativecommons.org/licenses/by-sa/3.0/igo). By using the content of this publication, the users accept to be bound by the terms of use of the UNESCO Open Access Repository (http://www.unesco.org/openaccess/terms-use-ccbysa-en).

\section{Disclaimer:}

The designations employed and the presentation of material throughout this publication do not imply the expression of any opinion whatsoever on the part of UNESCO concerning the legal status of any country, territory, city or area or of its authorities, or concerning the delimitation of its frontiers or boundaries. The ideas and opinions expressed in this publication are those of the authors; they are not necessarily those of UNESCO and do not commit the Organization.

\section{Citation:}

Rusinol, M. and Girones, R. (2017). Summary of Excreted and Waterborne Viruses. In: J.B. Rose and B. Jiménez-Cisneros, (eds) Water and Sanitation for the 21st Century: Health and Microbiological Aspects of Excreta and Wastewater Management (Global Water Pathogen Project). (J.S Meschke, and R. Girones (eds), Part 3: Specific Excreted Pathogens: Environmental and Epidemiology Aspects - Section 1: Viruses), Michigan State University, E. Lansing, MI, UNESCO. https://doi.org/10.14321/waterpathogens.19

Acknowledgements: K.R.L. Young, Project Design editor; Website Design: Agroknow (http://www.agroknow.com)

Last published: December 6, 2017 


\section{Summary}

There are hundreds of viruses that infect humans and most are released into feces and urine making their way into the environment by excretion or secretion of bodily fluids or skin cells. The viruses infecting the enteric track are known to be excreted in high numbers and many of these viruses are commonly excreted by healthy people often long after symptom resolution.

The most important excreted known pathogens are transmitted by a variety of means including fecal-oral transmission routes and are members of six families, Picornaviridae, Caliciviridae, Hepeviridae, Reoviridae, Astroviridae (all RNA viruses) and the DNA virus family Adenoviridae. Viruses in these families cause asymptomatic infections and also outbreaks or sporadic cases with a wide range of symptoms from mild to severe gastroenteritis to meningitis, respiratory disease, conjunctivitis, miocarditis, paralysis, or hepatitis.

Recent data have shown the presence of new viral pathogens associated with gastroenteritis or other clinical symptoms in a set of novel viral families. In the Parvoviridae family, human bocaviruses 1 to $4(\mathrm{HBoV})$ and human bufavirus $(\mathrm{HBuV})$ are associated with respiratory and gastrointestinal diseases. Circoviruses are currently known to infect birds and swine, and no human pathogenic circoviruses have been definitively demonstrated yet, nevertheles new phylogenetically diverse Circoviruses have been shown to be present in sewage. A large portion of circular ssDNA viruses similar to the family Circoviridae have been revealed primarily through metagenomics in a diverse range of samples. Metagenomics in raw sewage water of United States, Spain and Ethiopia, showed sequences with identities between 20 and 50\% to the Circoviridae family and in another study sewage from United States showed sequences 35 to $58 \%$ identical. The genera Cyclovirus have been suggested to cause human enteric infections and, a study identified and characterized the full genome of a novel cyclovirus (tentatively named cyclovirus-Vietnam [CyCV-VN]) in cerebrospinal fluid (CSF) specimens of two Vietnamese patients with CNS infections of unknown etiology.

A wide diversity of viruses is known to be commonly excreted, some are new pathogens recently described and some of them have not been associated yet to human diseases. A study analyzing stool samples from two healthy infant siblings collected at about weekly intervals during their first year of life were analyzed by PCR for 15 different enteric viral genera showed that ninety-two percent (66/72) of the fecal samples tested contained one to five different human viruses. Adenovirus, Aichi virus, Anellovirus,
Astrovirus, Bocavirus, Enterovirus, Parechovirus, Picobirnavirus, and Rotavirus were detected. The study also confirmed long-term virus shedding for adenoviruses, anelloviruses, bocaviruses, enteroviruses, parechoviruses, and picobirnaviruses.

Excreted viruses are detected in urban sewage samples and survival is facilitated by organic debris of the clinical matrix in which the virus is shed (feces or vomit) and virus aggregate formation, offering protection in the route to new human hosts. The concentration of viruses observed in urban sewage is high and is related to the epidemiology of each viral infection. Viruses excreted in the population of all geographical areas and without defined seasonability, as it is the case of human adenoviruses, have been detected in wastewater and superficial waters in all geographical areas analyzed with levels of $10^{4-7} \mathrm{GC} / 100 \mathrm{ml}$ in raw sewage, $10^{3-4}$ $\mathrm{GC} / 100 \mathrm{ml}$ in secondary and tertiary effluent of wastewater treatment plants, $10^{4-7} \mathrm{GC} / 100 \mathrm{~g}$ of biosolids, $10^{1-5} \mathrm{CG} / \mathrm{L}$ in river water, and $10^{1-3} \mathrm{CG} / \mathrm{L}$ in seawater. Human adenoviruses and human polyomaviruses have been suggested as indicators of human fecal/urine contamination and MST tools in the environment and water based on the affordability of quantification techniques for DNA viruses, and their abundance in all geographical areas and periods of the year. Many classical and emerging viral pathogens have been detected in bathing water, river and seawater and their high stability and low infectious doses support the need for improving control of virus dissemination in water is an important concern requiring improved water treatments and regulations.

There are hundreds of viruses that infect humans and are released into the environment by excretion or secretion of bodily fluids or skin. The viruses infecting the gastrointestinal tract also known as enteric viruses, are excreted in high numbers $\left(10^{7} 10^{9} \mathrm{~g}-1\right.$ of feces) by infected individuals with or without disease, and in some cases long after the resolution of disease. These viruses can be transmitted by contaminated water via the fecal-oral route.

\subsection{TAXONOMIC CLASSIFICATION OF THE VIRAL AGENTS}

The most important waterborne viruses are members of six families, including RNA virus families such as Picornaviridae, Caliciviridae, Hepeviridae, Reoviridae, Astroviridae and the Adenoviridae within the family of DNA viruses. Viruses in these families cause asymptomatic infections and also outbreaks or sporadic cases with a wide range of symptoms from mild to severe gastroenteritis to meningitis, respiratory disease, conjunctivitis, myocarditis, paralysis, or hepatitis (http://ictvonline.org). 
Table 1. Main viral waterborne pathogens

\begin{tabular}{|c|c|c|c|}
\hline Family (genome, size) & Genus & Most important human pathogens & Related diseases \\
\hline $\begin{array}{l}\text { Adenoviridae (dsDNA, } \\
\text { 70-90nm) }\end{array}$ & Mastadenovirus & Human adenovirus A-G (HAdV) & $\begin{array}{c}\text { Gastroenteritis, } \\
\text { respiratory disease, } \\
\text { conjunctivitis, } \\
\text { cystitis }\end{array}$ \\
\hline $\begin{array}{l}\text { Astroviridae (ssRNA, } \\
28-41 \mathrm{~nm})\end{array}$ & Mamastrovirus & Astrovirus 1-9 (HAstV) & $\begin{array}{l}\text { Gastroenteritis, } \\
\text { related to } \\
\text { respiratory } \\
\text { infections }\end{array}$ \\
\hline \multirow{2}{*}{$\begin{array}{l}\text { Caliciviridae (ssRNA, } \\
27-38 \mathrm{~nm})\end{array}$} & Norovirus & Norovirus GI, GII (NoV) & Gastroenteritis \\
\hline & Sapovirus & Sapovirus GI, GII, GIV, GV (SaV) & Gastroenteritis \\
\hline $\begin{array}{l}\text { Hepeviridae (ssRNA, } \\
25-30 \mathrm{~nm} \text { ) }\end{array}$ & Orthohepevirus & Hepatitis E virus $\mathrm{G} 1,2,3,4,7$ (HEV) & Acute hepatitis \\
\hline \multirow{4}{*}{$\begin{array}{l}\text { Picornaviridae (ssRNA, } \\
\text { 24-30nm) }\end{array}$} & Enterovirus & $\begin{array}{l}\text { Enterovirus A-D (EV-68 and EV-71), Rhinovirus A-C, } \\
\text { Poliovirus 1-3, Coxsakievirus A-B }\end{array}$ & $\begin{array}{c}\text { Paralysis, } \\
\text { meningitis, hand- } \\
\text { foot-and-mouth } \\
\text { disease, heart } \\
\text { anomalies, skin rush }\end{array}$ \\
\hline & Hepatovirus & Hepatitis A virus GI-III (HAV) & Acute hepatitis \\
\hline & Kobuvirus & Aichivirus A to $\mathrm{C}(\mathrm{AiV})$ & Gastroenteritis \\
\hline & Parechovirus & Parechovirus 1 to $16(\mathrm{PeV})$ & $\begin{array}{c}\text { Gastroenteritis, } \\
\text { respiratory } \\
\text { infections, } \\
\text { encephalitis, } \\
\text { meningitis, hepatitis }\end{array}$ \\
\hline $\begin{array}{l}\text { Reoviridae (dsRNA, } \\
70-75 \mathrm{~nm})\end{array}$ & Rotavirus & Rotavirus A to G (RoV) & Gastroenteritis \\
\hline
\end{tabular}

Reoviridae (dsRNA, (0-75nm)
Rotavirus

Rotavirus A to $\mathrm{G}(\mathrm{RoV})$

\subsection{Viral pathogens of primary concern for waterborne diseases}

1.1.2 Other groups containing new water-borne emerging viruses

Recent data has shown evidence of new viral pathogens in the Parvoviridae family associated with gastroenteritis in humans. The clinical manifestations of parvovirus 4 (PARV4) remain unknown whereas human bocaviruses 1 to $4(\mathrm{HBoV})$ and human bufavirus $(\mathrm{HBuV})$ are associated with respiratory and gastrointestinal diseases (Väisänen et al., 2014)

New viruses with DNA in circular form that are phylogenetically diverse have been detected in sewage. These viruses have been included within the family Circoviridae which comprises virus species that infect birds and swine (Blinkova et al., 2009). A large portion of circular
ssDNA viruses, similar to the family Circoviridae, was elucidated by metagenomics of a diverse range of samples. Metagenomics of urban sewage in the United States, Spain and Ethiopia, showed virome contigs with 20 to $50 \%$ similarities to viruses with circular genomes characteristic of the Circoviridae family (Cantalupo et al., 2011). In addition, PCR screening of viral nucleic acid recovered from sewage in the United States revealed genetic variants of DNA circoviruses (Blinkova et al., 2009). The genus Cyclovirus has been suggested to cause human enteric infections, and a study identified and characterized the full genome of a novel cyclovirus (tentatively named cyclovirusVietnam [CyCV-VN]) in cerebrospinal fluid (CSF) specimens of two Vietnamese patients with CNS infections of unknown etiology (Li et al., 2010; Phan et al., 2015). The authors suggested the potential for fecal-oral as well as foodborne transmission while high detection rates in feces from pigs and poultry (average, 58\%) suggested the existence of animal reservoirs for such transmission routes (Tan et al., 2013). 
Table 2. Emerging viruses with potential for water-borne transmission

\begin{tabular}{|c|c|c|c|}
\hline $\begin{array}{c}\text { Family } \\
\text { (genome, size) }\end{array}$ & Genus & Human pathogens & Related diseases \\
\hline $\begin{array}{l}\text { Anelloviridae (ssDNA, } \\
\text { 30-32nm) }\end{array}$ & Alphatorquevirus & Torquetenovirus (TTV) & $\begin{array}{c}\text { Asymptomatic. } \\
\text { May be associated with various diseases: } \\
\text { hepatitis, pulmonary diseases, } \\
\text { hematologic disorders, myopathy and } \\
\text { lupus. }\end{array}$ \\
\hline $\begin{array}{l}\text { Circoviridae (ssDNA, } \\
15-20 \mathrm{~nm})\end{array}$ & Cyclovirus & $\begin{array}{l}\text { Human Associated } \\
\text { Cyclovirus 1-11 (HuACyV) }\end{array}$ & $\begin{array}{c}\text { Systemic infections, may play a role in } \\
\text { development of paraplegia }\end{array}$ \\
\hline \multirow{3}{*}{$\begin{array}{l}\text { Parvoviridae (ssDNA, } \\
18-26 \mathrm{~nm} \text { ) }\end{array}$} & Erythroparvovirus & Parvovirus B19 (PaV) & $\begin{array}{l}\text { Fifth disease in children, arthropathy, } \\
\text { hepatitis }\end{array}$ \\
\hline & Bocaparvovirus & $\begin{array}{l}\text { Human bocavirus } 1-4 \\
\text { (HBoV) }\end{array}$ & $\begin{array}{c}\text { Gastroenteritis, related to respiratory } \\
\text { infections }\end{array}$ \\
\hline & Protoparvovirus & Bufavirus (HBuV) & Gastroenteritis \\
\hline \multirow{2}{*}{$\begin{array}{l}\text { Papillomaviridae } \\
\text { (dsDNA, 50-60nm) }\end{array}$} & Alpha-papillomavirus & $\begin{array}{c}\text { Human Papillomavirus 16, } \\
18 \text { (HPV) }\end{array}$ & Cervix, penis, anus and vulva cancers \\
\hline & Beta-papillomavirus & HPV 66 & Related to genital warts \\
\hline \multirow[t]{2}{*}{$\begin{array}{l}\text { Picobirnaviridae } \\
\text { (ssRNA, 33-41nm) }\end{array}$} & Picobirnavirus & $\begin{array}{l}\text { Human picobirnavirus } \\
\text { (HPBV) }\end{array}$ & $\begin{array}{c}\text { May be implicated in gastroenteritis in } \\
\text { humans }\end{array}$ \\
\hline & Betapolyomavirus & Polyomavirus JC (PyV) & $\begin{array}{l}\text { Progressive multifocal encephalopathy } \\
\text { (PML) }\end{array}$ \\
\hline \multirow[t]{2}{*}{$\begin{array}{l}\text { Polyomaviridae } \\
\text { (dsDNA, 50-60nm) }\end{array}$} & & BKPyV & $\begin{array}{l}\text { Mild respiratory infection, polyomavirus- } \\
\text { associated nephropathy polyomavirus- } \\
\text { associated haemorrhagic cystitis }\end{array}$ \\
\hline & Alphapolyomavirus & Merkel cell PyV (MCPyV) & Associated to merkel cell carcinoma \\
\hline
\end{tabular}

\subsection{EXCRETION OF VIRUSES}

The excretion of viruses in feces is high and viruses are commonly excreted by healthy people even after resolution of symptoms. Stool samples from healthy infants showed that ninety-two percent (66/72) of the tested fecal samples contained one to five different human viruses (Kapusinszky et al., 2012). Adenoviruses, aichi viruses, anelloviruses, astroviruses, bocaviruses, enteroviruses, parechoviruses, picobirnaviruses and rotaviruses were the viruses most frequently detected. Vaccination schedules have an effect on the excretion of viruses (Laassri et al., 2005). The summary of the level of excretion of the most important waterborne viruses is shown in Table 3.

Table 3. Summary of the excretion characteristics of main water-borne viral pathogens

\begin{tabular}{|c|c|c|c|c|}
\hline Viral Pathogen & $\begin{array}{c}\text { Excretion } \\
\text { concentrations }\end{array}$ & Clinical characteristics & Prevalence in feces/urine & Reference \\
\hline Adenovirus & $\begin{array}{c}\mathrm{E}+07 \text { to } \mathrm{E}+11 \mathrm{GC} / \mathrm{g} \text { of } \\
\text { stool }\end{array}$ & $\begin{array}{c}\text { IP: } 3 \text { to } 10 \text { days } \\
\text { ID: } 1 \text { to } 4 \text { days } \\
\text { DE: } 11 \text { days ( } 1 \text { to } 192)\end{array}$ & $\begin{array}{l}2.6 \% \text { to } 16 \% \text { in fecal } \\
\text { gastroenteritis samples }\end{array}$ & $\begin{array}{l}\text { Bozkurt et al., } \\
\text { 2015; Lion et } \\
\text { al., 2010; } \\
\text { Rimoldi et al., } \\
2011\end{array}$ \\
\hline Aichivirus & $\begin{array}{c}\mathrm{E}+06 \text { to } \mathrm{E}+12 \mathrm{GC} / \mathrm{g} \text { of } \\
\text { stool }\end{array}$ & $\begin{array}{c}\text { IP: } 12 \text { to } 54 \mathrm{~h} \\
\text { ID: } 2 \text { to } 3 \text { days } \\
\text { DE: Undetermined }\end{array}$ & $\begin{array}{l}0.8 \% \text { in fecal gastroenteritis } \\
\text { samples }\end{array}$ & $\begin{array}{l}\text { Bozkurt et al., } \\
\text { 2015; Drexler et } \\
\text { al., 2011; Le } \\
\text { Guyader et al., } \\
2008\end{array}$ \\
\hline
\end{tabular}




\begin{tabular}{|c|c|c|c|c|}
\hline Viral Pathogen & $\begin{array}{c}\text { Excretion } \\
\text { concentrations }\end{array}$ & Clinical characteristics & Prevalence in feces/urine & Reference \\
\hline Astrovirus & $\begin{array}{c}\mathrm{E}+08 \text { to } \mathrm{E}+13 \mathrm{GC} / \mathrm{g} \text { of } \\
\text { stool }\end{array}$ & $\begin{array}{l}\text { IP: } 3,9 \text { to } 5,2 \text { days } \\
\text { ID: } 1 \text { to } 4 \text { days } \\
\text { DE: } 2 \text { to } 30 \text { days }\end{array}$ & $\begin{array}{l}11 \% \text { mean incidence of } \\
\text { gastroenteritis worldwide, with } \\
7 \% \text { and } 23 \% \text { incidences in } \\
\text { urban and rural areas }\end{array}$ & $\begin{array}{c}\text { Bosch et } \\
\text { al.,2013; } \\
\text { Caballero et al., } \\
\text { 2003; } \\
\text { Desselberger } \\
\text { and Gray, 1995; } \\
\text { Lee et al., } 2013\end{array}$ \\
\hline Bocavirus & $\begin{array}{l}\mathrm{E}+04 \mathrm{GC} / \mathrm{ml} \text { of fecal } \\
\text { supernatant }\end{array}$ & $\begin{array}{l}\text { IP: Undetermined } \\
\text { ID: } 1 \text { to } 4 \text { days } \\
\text { DE: weeks }\end{array}$ & $\begin{array}{c}1.3 \% \text { in fecal gastroenteritis } \\
\text { samples }\end{array}$ & $\begin{array}{l}\text { Lau et al., 2007; } \\
\text { Proenca-Modena } \\
\text { et al., 2013; } \\
\text { Rimoldi et al., } \\
2011\end{array}$ \\
\hline Enterovirus & $\begin{array}{l}\text { Coxsackievirus: E+03 to } \\
\text { E+06 TCID50/g of stool }\end{array}$ & $\begin{array}{c}\text { IP: } 2 \text { days } \\
\text { ID: } 2 \text { to } 3 \text { days } \\
\text { DE: } 50 \text { days (44 to } 142 \text { ) }\end{array}$ & $\begin{array}{l}22.1 \% \text { coxsackievirus in fecal } \\
\text { gastroenteritis samples }\end{array}$ & $\begin{array}{l}\text { Bozkurt et al., } \\
\text { 2015; Melnick } \\
\text { and Rennick, } \\
\text { 1980; } \\
\text { Khetsuriani et } \\
\text { al., } 2009\end{array}$ \\
\hline Hepatitis A & $\begin{array}{l}\mathrm{E}+07 \mathrm{GC} / \mathrm{ml} \text { of fecal } \\
\text { supernatant }\end{array}$ & $\begin{array}{l}\text { IP: } 7 \text { to } 50 \text { days } \\
\text { ID: } 3 \text { to } 6 \text { months } \\
\text { DE: } 8 \text { days }(4 \text { to } 42)\end{array}$ & $20 \%$ of clinical hepatitis & $\begin{array}{l}\text { Arankalle et al., } \\
\text { 2006; Lee, } 2000\end{array}$ \\
\hline Hepatitis E & $\begin{array}{l}\mathrm{E}+03 \text { to } \mathrm{E}+07 \mathrm{GC} / \mathrm{ml} \text { of } \\
\text { fecal supernatant }\end{array}$ & $\begin{array}{c}\text { IP: } 2 \text { to } 10 \text { weeks } \\
\text { ID: } 2 \text { to } 6 \text { weeks } \\
\text { DE: } 22 \text { days (14 to } 33)\end{array}$ & $\begin{array}{l}70 \% \text { of fecal samples from } \\
\text { hepatitis patients }\end{array}$ & $\begin{array}{l}\text { Chandra et al., } \\
\text { 2010.; Kim et } \\
\text { al., } 2014 \text {; } \\
\text { Takahashi et al., } \\
2007\end{array}$ \\
\hline Norovirus & $\begin{array}{c}\mathrm{E}+07 \text { to } \mathrm{E}+09 \mathrm{GC} / \mathrm{gr} \text { of } \\
\text { stool }\end{array}$ & $\begin{array}{l}\text { IP: } 1,1 \text { to } 1,2 \text { days } \\
\text { ID: } 12 \text { to } 60 \mathrm{~h} \\
\text { DE: } 28 \text { days (13 to } 56)\end{array}$ & $\begin{array}{l}16.2 \text { to } 42.8 \% \text { in fecal } \\
\text { gastroenteritis samples }\end{array}$ & $\begin{array}{l}\text { Atmar et al., } \\
\text { 2008; Bozkurt et } \\
\text { al., 2015; } \\
\text { Kaplan et al., } \\
\text { 1982; Lee et al., } \\
\text { 2013; Rimoldi et } \\
\text { al., } 2011\end{array}$ \\
\hline Polyomavirus & $\mathrm{E}+05 \mathrm{GC} / \mathrm{ml}$ urine & $\begin{array}{l}\text { Reactivation in patients } \\
\text { with immunosuppressive } \\
\text { conditions } \\
\text { DE: Several months or } \\
\text { years }\end{array}$ & $\begin{array}{c}62.7 \% \text { of helthy adults and } \\
13.2 \% \text { of children excrete } \\
\text { polyomaviruses in theurine, } \\
\text { mostly JC virus }(41.2 \%)\end{array}$ & $\begin{array}{l}\text { Bofill-Mas and } \\
\text { Girones, 2001; } \\
\text { Kling et al., } \\
\text { 2012; Polo et al., } \\
2004\end{array}$ \\
\hline Rotavirus & $\begin{array}{c}\mathrm{E}+10 \text { to } \mathrm{E}+12 \mathrm{GC} / \mathrm{gr} \text { of } \\
\text { stool }\end{array}$ & $\begin{array}{c}\text { IP: } 2 \text { days } \\
\text { ID: } 3 \text { to } 8 \text { days } \\
\text { DE: } 10 \text { days ( } 4 \text { to } 57 \text { ) }\end{array}$ & $\begin{array}{l}33 \text { to } 38.2 \% \text { in fecal } \\
\text { gastroenteritis samples }\end{array}$ & $\begin{array}{c}\text { Bozkurt et al., } \\
\text { 2015; } \\
\text { Desselberger } \\
\text { and Gray, 1995; } \\
\text { Ramani et al., } \\
\text { 2014; } \\
\text { Richardson et } \\
\text { al., 1998; } \\
\text { Rimoldi et al., } \\
2011\end{array}$ \\
\hline Sapovirus & $\begin{array}{c}\mathrm{E}+07 \text { to } \mathrm{E}+08 \mathrm{GC} / \mathrm{g} \text { of } \\
\text { stool }\end{array}$ & $\begin{array}{c}\text { IP: } 1,7 \text { days } \\
\text { ID: } 1 \text { to } 4 \text { days } \\
\text { DE: } 4 \text { days ( } 4 \text { to } 21)\end{array}$ & $\begin{array}{l}3.8 \% \text { in fecal gastroenteritis } \\
\text { samples }\end{array}$ & $\begin{array}{l}\text { Bozkurt et al., } \\
\text { 2015; Lee et al., } \\
\text { 2013; Rimoldi et } \\
\text { al., 2011; Rockx } \\
\text { et al., 2002; } \\
\text { Torner et al., } \\
2016\end{array}$ \\
\hline
\end{tabular}

IP: Incubation Period, ID: Illness duration, DE: days excretion 


\subsection{TRANSMISSION}

\subsubsection{Global routes of transmission for viral infections}

Water and food are the main vehicles for transmission of viruses that replicate in the gastrointestinal tract causing the wide spectrum of diseases described in Table 2. Contaminated drinking water is an important cause of gastrointestinal disease (Altzibar et al., 2015; Braeye et al., 2015; Craun et al., 2010; Kauppinen et al., 2017). The burden of water-borne diseases directly related to viruses, was estimated at 136 outbreaks in Europe during 2000 and 2007 (39\% of all diarrhea cases due to unsafe water) and at 64 outbreaks in the U.S. during 1971 and 2006 (Craun et al., 2010; ENHIS, 2009). The risk of emerging waterborne diseases increases where standards of water, sanitation and personal hygiene are low. More than half of the waterborne disease outbreaks linked to drinking water have been associated with untreated or inadequately treated ground water, indicating that contamination of ground water remains a public health problem (Yoder et al., 2011).

The global public health impact is higher when considering the food-borne transmission route. The American and European surveillance reports on the foodborne outbreaks estimate that between 45 and $51 \%$ of the total food-borne outbreaks are caused by water-borne viruses (Gould et al., 2013; Price-Hayward and Hartnell, 2016). The route from food production to consumption is very complex, with many points where pathogens can enter and reach the consumers (e.g. at the farm, during slaughter, during processing, in the kitchen). Of the viral pathogens that can contaminate food, HAV, HEV and NoV in bivalve shellfish, fresh produce, and prepared foods have been identified as the highest risk pathogens (EFSA, 2012). Foodborne cases of hepatitis $\mathrm{E}$ in humans are increasingly common and likely underestimated in the medical community (Meng, 2013). Sporadic and cluster cases of hepatitis E occur after consumption of undercooked or raw animal meats.

Table 4. Transmission routes of the principal waterborne viruses

\begin{tabular}{|c|c|c|c|}
\hline Viral Pathogen & Transmission routes & Seasonality & Reference \\
\hline Adenovirus & $\begin{array}{l}\text { Fecal-oral: contaminated food, person-to- } \\
\text { person, drinking water } \\
\text { Airborne: respiratory secretions } \\
\text { Bathing water }\end{array}$ & Without clear seasonality & $\begin{array}{l}\text { Mena and Gerba, } \\
\text { 2009; Vetter et al., } \\
2015\end{array}$ \\
\hline Aichivirus & $\begin{array}{l}\text { Fecal-oral: contaminated food, person-to- } \\
\text { person, drinking water }\end{array}$ & Without clear seasonality & $\begin{array}{l}\text { Kitajima and Gerba, } \\
2015\end{array}$ \\
\hline Astrovirus & $\begin{array}{l}\text { Fecal-oral: contaminated food, person-to- } \\
\text { person, drinking water }\end{array}$ & $\begin{array}{l}\text { Higher incidence in the cold- } \\
\text { weather period }\end{array}$ & Bosch et al., 2014 \\
\hline Bocavirus & $\begin{array}{c}\text { Fecal-oral: drinking water } \\
\text { Airborne: aerosol, respiratory secretions } \\
\text { Vertical transmission? }\end{array}$ & $\begin{array}{l}\text { Higher prevalences in cold } \\
\text { months }\end{array}$ & $\begin{array}{l}\text { Hamza et al., 2009; } \\
\text { Schildgen et al., } 2008\end{array}$ \\
\hline Enterovirus & $\begin{array}{l}\text { Fecal-oral: drinking water } \\
\text { Respiratory secretions }\end{array}$ & $\begin{array}{l}\text { Higher prevalences in } \\
\text { warm/wet seasons }\end{array}$ & Sedmak et al., 2005 \\
\hline Hepatitis A & $\begin{array}{l}\text { Fecal-oral: contaminated food, person-to- } \\
\text { person }\end{array}$ & No clear seasonality & $\begin{array}{l}\text { Fares, 2015; Ouardani } \\
\text { et al., } 2016\end{array}$ \\
\hline Hepatitis E & $\begin{array}{l}\text { Fecal-oral: contaminated food, drinking } \\
\text { water } \\
\text { Foodborne: raw meat }\end{array}$ & $\begin{array}{l}\text { Occurs more frequently in } \\
\text { winter }\end{array}$ & $\begin{array}{l}\text { Inoue et al., 2009; } \\
\text { Kotwal and Cannon, } \\
2014\end{array}$ \\
\hline Norovirus & $\begin{array}{l}\text { Fecal-oral: contaminated food, person-to- } \\
\text { person, drinking water }\end{array}$ & $\begin{array}{l}\text { Higher prevalences in cold } \\
\text { months }\end{array}$ & de Graaf et al., 2016 \\
\hline Polyomavirus & $\begin{array}{l}\text { The route of intra-human transmission is } \\
\text { still unknown }\end{array}$ & Without seasonal distribution & Fratini et al., 2014 \\
\hline Rotavirus & $\begin{array}{l}\text { Fecal-oral: contaminated food, person-to- } \\
\text { person, drinking water }\end{array}$ & $\begin{array}{l}\text { Year-round infection in } \\
\text { countries within } 10 \text { degrees } \\
\text { of the equator, Winter peaks } \\
\text { in all other regions of the } \\
\text { world }\end{array}$ & Estes et al., 1983 \\
\hline Sapovirus & Fecal-oral: drinking water & $\begin{array}{l}\text { Peak observed mainly in the } \\
\text { cold season }\end{array}$ & Dey et al., 2012 \\
\hline
\end{tabular}




\subsubsection{Animal Reservoirs of viral infections in humans}

Humans are the main reservoirs of enteric viruses. With exception of rotavirus and hepatitis E virus, zoonotic transmission of water-borne viruses is rare. It is a wellknown fact that animal RoV-A infect humans. Nowadays, there is convincing genetic evidence that interspecies transmission of RoV occurs. Animal RoV can infect humans via direct interspecies transmission events or reassortment between a human and animal rotavirus. Recent reviews on porcine, bovine and equine rotaviruses indicate that there are some globally important genotype specificities of RoVs in each of these host species. (Papp et al., 2013a; Papp et al., 2013b). Nevertheless, zoonotic viruses can emerge from animal reservoirs and affect humans only incidentally.

Hepatitis E virus is an emerging zoonotic water- and foodborne pathogen (Ricci et al., 2017; Uddin Khan et al., 2013). HEV-1 and HEV-2 are restricted to humans whereas HEV-3 and HEV-4 are naturally present in several animal species and can cross the species barrier. The zoonotic transmission of HEV-3 and HEV-4 from swine, wild boar and deer to human via the consumption of raw meat has been proven (Bouquet et al., 2012, 2011; Cook et al., 2017). In 2016, a small outbreak in China was related to HEV-4 found in food from the company's cafeteria (Zhang et al., 2016). There is also an increasing evidence for zoonotic transmission of hepatitis E from camels (Sridhar et al., 2017).

\subsection{DATA ON OCCURRENCE OF VIRUSES IN WASTE WATER}

Waterborne viral diseases are of major concern in both developing and developed countries and wastewater treatment plays a crucial role in mitigating viral pollution of aquatic environments. A summary of representative available data on the occurrence of viral pathogens in raw sewage, secondary and tertiary effluents of wastewater treatment plants is shown in Tables 5, 6 and 7.

Table 5. Viral concentrations in wastewater effluents worldwide

\begin{tabular}{|c|c|c|c|c|c|}
\hline Area & Viral Pathogen & $\begin{array}{l}\text { Percent Positive } \\
\text { (\# of samples) }\end{array}$ & $\begin{array}{c}\text { Mean concentration } \\
\text { (GC/L) }\end{array}$ & $\begin{array}{c}\text { Max concentration } \\
\text { (GC/L) }\end{array}$ & Reference \\
\hline Asia & Norovirus GGII & 36 & $2.51 \mathrm{E}+06$ & $\mathrm{NR}^{\mathrm{a}}$ & $\begin{array}{c}\text { Eftim et al., } \\
2017\end{array}$ \\
\hline Bolivia & Rotavirus & NR & $3.1 \mathrm{E}+07$ & NR & $\begin{array}{l}\text { Symonds et } \\
\text { al., } 2014\end{array}$ \\
\hline Brazil & Hepatitis A & $\begin{array}{l}25 \% \\
(6 / 22)\end{array}$ & $5.1 \mathrm{E}+02$ & NR & $\begin{array}{l}\text { Villar et al., } \\
2007\end{array}$ \\
\hline Brazil & Polyomavirus & $\begin{array}{c}96 \% \\
(23 / 24)\end{array}$ & $4.6 \mathrm{E}+05$ & $3.2 \mathrm{E}+05$ & $\begin{array}{c}\text { Fumian et } \\
\text { al., } 2010\end{array}$ \\
\hline \multirow[t]{2}{*}{ Brazil } & Rotavirus & $\begin{array}{c}70.6 \% \\
(17 / 24)\end{array}$ & NR & $2.9 \mathrm{E}+08$ & $\begin{array}{l}\text { Prado et al., } \\
2011\end{array}$ \\
\hline & Adenovirus & $\begin{array}{c}100 \% \\
(16 / 16)\end{array}$ & $9.16 \mathrm{E}+06$ & NR & \multirow{4}{*}{$\begin{array}{l}\text { Qiu et al., } \\
2015\end{array}$} \\
\hline \multirow{3}{*}{ Canada } & Enterovirus & $\begin{array}{c}100 \% \\
(16 / 16)\end{array}$ & $4.08 \mathrm{E}+04$ & NR & \\
\hline & Norovirus GGII & $\begin{array}{c}100 \% \\
(16 / 16)\end{array}$ & $1.2 \mathrm{E}+06$ & NR & \\
\hline & Sapovirus & $\begin{array}{l}12.5 \% \\
(2 / 16)\end{array}$ & $\mathrm{E}+07$ & NR & \\
\hline Europe & Norovirus GGII & 305 & $\mathrm{E}+05$ & NR & $\begin{array}{c}\text { Eftim et al., } \\
2017\end{array}$ \\
\hline France & Astrovirus & $\begin{array}{c}82 \% \\
(14 / 17)\end{array}$ & $4.1 \mathrm{E}+06$ & $3.1 \mathrm{E}+07$ & $\begin{array}{l}\text { Le Cann et } \\
\text { al., } 2004\end{array}$ \\
\hline \multirow{2}{*}{ Germany } & Adenovirus & $\begin{array}{c}100 \% \\
(13 / 13)\end{array}$ & $1.24 \mathrm{E}+06$ & NR & \multirow{2}{*}{$\begin{array}{l}\text { Leifels et } \\
\text { al., } 2016\end{array}$} \\
\hline & Enterovirus & $\begin{array}{c}92 \% \\
(12 / 13)\end{array}$ & $2.27 \mathrm{E}+05$ & NR & \\
\hline Italy & Bocavirus & $\begin{array}{c}76 \% \\
(102 / 134)\end{array}$ & $4.7 \mathrm{E}+04$ & $E+05$ & $\begin{array}{l}\text { Iaconelli et } \\
\text { al., } 2016\end{array}$ \\
\hline Japan & Adenovirus & $\begin{array}{c}100 \% \\
(72 / 72)\end{array}$ & $5.5 \mathrm{E}+06$ & NR & $\begin{array}{l}\text { Katayama } \\
\text { et al., } 2008\end{array}$ \\
\hline
\end{tabular}




\begin{tabular}{|c|c|c|c|c|c|}
\hline Area & Viral Pathogen & $\begin{array}{l}\text { Percent Positive } \\
\text { (\# of samples) }\end{array}$ & $\begin{array}{c}\text { Mean concentration } \\
(\mathrm{GC} / \mathrm{L})\end{array}$ & $\begin{array}{c}\text { Max concentration } \\
\text { (GC/L) }\end{array}$ & Reference \\
\hline \multirow{3}{*}{ Japan } & Astrovirus & $\begin{array}{c}36 \% \\
(10 / 28)\end{array}$ & $1.7 \mathrm{E}+06$ & NR & \multirow{3}{*}{$\begin{array}{l}\text { Kobayashi } \\
\text { et al., } 2017\end{array}$} \\
\hline & Hepatitis A & $\begin{array}{c}7 \% \\
(2 / 28)\end{array}$ & $9.7 \mathrm{E}+02$ & $1.8 \mathrm{E}+03$ & \\
\hline & Hepatitis E & $\begin{array}{l}11 \% \\
(3 / 28)\end{array}$ & $1.7 \mathrm{E}+02$ & $6.4 \mathrm{E}+03$ & \\
\hline \multirow{3}{*}{ Japan } & Enterovirus & $\begin{array}{c}65 \% \\
(47 / 72)\end{array}$ & $2.95 \mathrm{E}+05$ & NR & \multirow{3}{*}{$\begin{array}{l}\text { Katayama } \\
\text { et al., } 2008\end{array}$} \\
\hline & Norovirus GGI & $\begin{array}{c}94 \% \\
(68 / 72)\end{array}$ & $\begin{array}{c}3.6 \mathrm{E}+07 \text { winter } \\
2.39 \mathrm{E}+04 \text { summer }\end{array}$ & NR & \\
\hline & Norovirus GGII & $\begin{array}{c}92 \% \\
(66 / 72)\end{array}$ & $\begin{array}{l}3.9 \mathrm{E}+07 \text { winter } \\
8.3 \mathrm{E}+04 \text { summer }\end{array}$ & NR & \\
\hline Japan & Sapovirus & $\begin{array}{c}100 \% \\
(12 / 12)\end{array}$ & $1.8 \mathrm{E}+04$ & $1.3 \mathrm{E}+05$ & $\begin{array}{l}\text { Haramoto } \\
\text { et al., } 2008\end{array}$ \\
\hline Japan & Polyomavirus & $\begin{array}{c}7 \% \\
(2 / 28)\end{array}$ & $2.7 \mathrm{E}+02$ & $7.2 \mathrm{E}+02$ & $\begin{array}{l}\text { Kobayashi } \\
\text { et al., } 2017\end{array}$ \\
\hline Nepal & Aichivirus & $\begin{array}{c}100 \% \\
(1 / 1)\end{array}$ & NR & $4.0 \mathrm{E}+09$ & $\begin{array}{c}\text { Haramoto } \\
\text { and } \\
\text { Kitajima, } \\
2017\end{array}$ \\
\hline $\begin{array}{l}\text { New } \\
\text { Zealand }\end{array}$ & Enterovirus & $\begin{array}{l}100 \\
(30)\end{array}$ & NR & $4.7 \mathrm{E}+06$ & $\begin{array}{l}\text { Hewitt et } \\
\text { al., } 2011\end{array}$ \\
\hline $\begin{array}{l}\text { New } \\
\text { Zealand }\end{array}$ & Norovirus GGII & 13 & $6.31 \mathrm{E}+03$ & NR & $\begin{array}{l}\text { Eftim et al., } \\
\quad 2017\end{array}$ \\
\hline $\begin{array}{l}\text { North } \\
\text { America }\end{array}$ & Norovirus GGII & 107 & $5.01 \mathrm{E}+04$ & NR & $\begin{array}{l}\text { Eftim et al., } \\
\quad 2017\end{array}$ \\
\hline \multirow{2}{*}{ Spain } & Adenovirus & $\begin{array}{c}89 \% \\
(33 / 37)\end{array}$ & $8.38 \mathrm{E}+05$ & $2.9 \mathrm{E}+07$ & \multirow{2}{*}{$\begin{array}{l}\text { Rusiñol et } \\
\text { al., } 2015\end{array}$} \\
\hline & Polyomavirus & $\begin{array}{c}100 \% \\
(37 / 37)\end{array}$ & $7.47 \mathrm{E}+05$ & $1.7 \mathrm{E}+07$ & \\
\hline \multirow{2}{*}{ Spain } & Norovirus GGI & $\begin{array}{c}91 \% \\
(49 / 54)\end{array}$ & NR & $5.9 \mathrm{E}+08$ & \multirow{2}{*}{$\begin{array}{l}\text { Pérez-Sautu } \\
\text { et al., } 2012\end{array}$} \\
\hline & Norovirus GGII & $\begin{array}{c}98 \% \\
(53 / 54)\end{array}$ & NR & $3.4 \mathrm{E}+09$ & \\
\hline Sweden & Adenovirus & $\begin{array}{l}100 \% \\
(7 / 7)\end{array}$ & $4.42 \mathrm{E}+06$ & $9.3 \mathrm{E}+06$ & $\begin{array}{l}\text { Hellmér et } \\
\text { al., } 2014\end{array}$ \\
\hline Switzerland & Hepatitis E & $\begin{array}{l}31 \% \\
(5 / 31)\end{array}$ & $7.81 \mathrm{E}+04$ & NR & $\begin{array}{l}\text { Masclaux et } \\
\text { al., } 2013\end{array}$ \\
\hline Uruguay & Astrovirus & $\begin{array}{c}45 \\
(19 / 45)\end{array}$ & NR & $4.3 \mathrm{E}+07$ & $\begin{array}{l}\text { Victoria et } \\
\text { al., } 2014\end{array}$ \\
\hline USA & Adenovirus & $\begin{array}{l}100 \% \\
(48 / 48)\end{array}$ & $1.55 \mathrm{E}+07$ & NR & $\begin{array}{l}\text { Schmitz et } \\
\text { al., } 2016\end{array}$ \\
\hline USA & Aichivirus & $\begin{array}{l}100 \% \\
(11 / 11)\end{array}$ & $1.18 \mathrm{E}+04$ & NR & $\begin{array}{l}\text { Rachmadi } \\
\text { et al., } 2016\end{array}$ \\
\hline
\end{tabular}

${ }^{a}$ NR: Not reported 
Table 6. Viral concentrations in secondary effluents worldwide

\begin{tabular}{|c|c|c|c|c|c|}
\hline Area & Viral Pathogen & $\begin{array}{c}\text { Percent Positive } \\
\text { (\# of samples) }\end{array}$ & $\begin{array}{c}\text { Mean concentration } \\
(\mathrm{GC} / \mathrm{L})\end{array}$ & Treatment & Reference \\
\hline \multirow{3}{*}{ Brazil } & Adenovirus & $\begin{array}{l}70 \% \\
(5 / 7)\end{array}$ & $3.78 \mathrm{E}+03$ & CAS & \multirow{3}{*}{$\begin{array}{l}\text { Prado et } \\
\text { al., } 2011\end{array}$} \\
\hline & Norovirus GGII & $\begin{array}{l}28.5 \% \\
(4 / 14)\end{array}$ & $2.4 \mathrm{E}+06$ & CAS & \\
\hline & Rotavirus & $\begin{array}{l}71 \% \\
(3 / 5)\end{array}$ & $1.9 \mathrm{E}+04$ & CAS & \\
\hline Brazil & Polyomavirus & $\begin{array}{c}39 \% \\
(9 / 23)\end{array}$ & $4.3 \mathrm{E}+04$ & CAS & $\begin{array}{l}\text { Fumian et } \\
\text { al., } 2010\end{array}$ \\
\hline Canada & Adenovirus & $\begin{array}{c}100 \% \\
(16 / 16)\end{array}$ & $9.08 \mathrm{E}+04$ & CAS & $\begin{array}{l}\text { Qiu et al., } \\
2015\end{array}$ \\
\hline \multirow{5}{*}{ France } & Aichi virus & $\begin{array}{c}84 \% \\
(231 / 275)\end{array}$ & $1.55 \mathrm{E}+03$ & CAS & \multirow{5}{*}{$\begin{array}{l}\text { Prevost et } \\
\text { al., } 2015\end{array}$} \\
\hline & Astrovirus & $\begin{array}{c}84 \% \\
(231 / 275)\end{array}$ & $1.08 \mathrm{E}+05$ & CAS & \\
\hline & Enterovirus & $\begin{array}{c}64 \% \\
(175 / 275)\end{array}$ & $1.0 \mathrm{E}+02$ & CAS & \\
\hline & Norovirus GGI & $\begin{array}{c}98 \% \\
(270 / 275)\end{array}$ & $5.0 \mathrm{E}+03$ & CAS & \\
\hline & Rotavirus & $\begin{array}{c}84 \% \\
(231 / 275)\end{array}$ & $2.11 \mathrm{E}+05$ & CAS & \\
\hline \multirow{2}{*}{ Germany } & Enterovirus & $\begin{array}{c}46 \% \\
(6 / 13)\end{array}$ & $8.63 \mathrm{E}+03$ & CAS & \multirow{2}{*}{$\begin{array}{l}\text { Leifels et } \\
\text { al., } 2016\end{array}$} \\
\hline & Rotavirus & $\begin{array}{c}77 \% \\
(10 / 13)\end{array}$ & $1.3 \mathrm{E}+04$ & CAS & \\
\hline Italy & Hepatitis A & $\begin{array}{c}14 \% \\
(3 / 21)\end{array}$ & Undetermined & CAS & $\begin{array}{l}\text { Iaconelli et } \\
\text { al., } 2015\end{array}$ \\
\hline \multirow{9}{*}{ Japan } & Aichi virus & $\begin{array}{c}71 \% \\
(20 / 28)\end{array}$ & $5.5 \mathrm{E}+02$ & DHS & \multirow{9}{*}{$\begin{array}{l}\text { Kobayashi } \\
\text { et al., } \\
2017\end{array}$} \\
\hline & Astrovirus & $\begin{array}{c}32 \% \\
(9 / 28)\end{array}$ & $6.3 E+03$ & DHS & \\
\hline & Enterovirus & $\begin{array}{l}21 \% \\
(6 / 28)\end{array}$ & $8.0 \mathrm{E}+02$ & DHS & \\
\hline & Henatitis A & $4 \%$ & $15 \mathrm{~F}+03$ & DHS & \\
\hline & пераuis A & $(1 / 28)$ & $1.5 \mathrm{E}+\mathrm{US}$ & DПऽ & \\
\hline & Hepatitis E & $\begin{array}{c}0 \% \\
(0 / 28)\end{array}$ & Non detected & DHS & \\
\hline & Norovirus GGI & $\begin{array}{c}14 \% \\
(4 / 28)\end{array}$ & $6.5 \mathrm{E}+01$ & DHS & \\
\hline & Norovirus GGII & $\begin{array}{c}57 \% \\
(16 / 28)\end{array}$ & $7.2 \mathrm{E}+01$ & DHS & \\
\hline & Rotavirus & $\begin{array}{c}11 \% \\
(3 / 28)\end{array}$ & $4.3 \mathrm{E}+02$ & DHS & \\
\hline \multirow[t]{2}{*}{ Japan } & Sapovirus & $\begin{array}{l}58 \% \\
(7 / 12)\end{array}$ & $1.5 \mathrm{E}+02$ & CAS & \multirow[t]{2}{*}{$\begin{array}{c}\text { Haramoto } \\
\text { et al., } \\
2008\end{array}$} \\
\hline & Bocavirus & $\begin{array}{c}54 \% \\
(14 / 26)\end{array}$ & $2.72 \mathrm{E}+04$ & CAS & \\
\hline \multirow[t]{2}{*}{ Norway } & Hepatitis E & $\begin{array}{c}8 \% \\
(2 / 26)\end{array}$ & Undetermined & CAS & \multirow[t]{2}{*}{$\begin{array}{l}\text { Myrmel et } \\
\text { al., } 2015\end{array}$} \\
\hline & Norovirus GGI & $\begin{array}{c}100 \% \\
(26 / 26)\end{array}$ & $3.8 \mathrm{E}+06$ & CAS & \\
\hline \multirow{2}{*}{ Singapore } & Astrovirus & $\begin{array}{c}100 \% \\
(18 / 18)\end{array}$ & $3.9 \mathrm{E}+04$ & CAS & \multirow{2}{*}{$\begin{array}{l}\text { Aw and } \\
\text { Gin, } 2010\end{array}$} \\
\hline & Hepatitis A & $\begin{array}{c}28 \% \\
(5 / 18)\end{array}$ & Undetermined & CAS & \\
\hline
\end{tabular}




\begin{tabular}{|c|c|c|c|c|c|}
\hline Area & Viral Pathogen & $\begin{array}{l}\text { Percent Positive } \\
\text { (\# of samples) }\end{array}$ & $\begin{array}{c}\text { Mean concentration } \\
(\mathrm{GC} / \mathrm{L})\end{array}$ & Treatment & Reference \\
\hline \multirow{3}{*}{ Spain } & Adenovirus & $\begin{array}{c}78 \% \\
(25 / 32)\end{array}$ & $1.2 \mathrm{E}+05$ & CAS & \multirow{3}{*}{$\begin{array}{l}\text { Rusiñol et } \\
\text { al., } 2015\end{array}$} \\
\hline & Norovirus GGII & $\begin{array}{c}65 \% \\
(21 / 32)\end{array}$ & $5.05 \mathrm{E}+05$ & CAS & \\
\hline & Polyomavirus & $\begin{array}{c}59 \% \\
(19 / 32)\end{array}$ & $1.6 \mathrm{E}+05$ & CAS & \\
\hline Sweden & Norovirus GGII & $\begin{array}{c}100 \% \\
(12 / 12)\end{array}$ & $1.0 \mathrm{E}+05$ & CAS & $\begin{array}{c}\text { Nordgren } \\
\text { et al., } \\
2009\end{array}$ \\
\hline \multirow{3}{*}{$\begin{array}{l}\text { United } \\
\text { Kingdom }\end{array}$} & Adenovirus & $\begin{array}{l}10 \% \\
(5 / 48)\end{array}$ & $1.1 \mathrm{E}+01$ & MBR & \multirow{3}{*}{$\begin{array}{l}\text { Purnell et } \\
\text { al., } 2016\end{array}$} \\
\hline & Norovirus GGI & $\begin{array}{c}3 \% \\
(1 / 48)\end{array}$ & $1.1 \mathrm{E}+01$ & MBR & \\
\hline & Norovirus GGII & $\begin{array}{c}6 \% \\
(2 / 48)\end{array}$ & $1.1 \mathrm{E}+01$ & MBR & \\
\hline
\end{tabular}

CAS: conventional activated sludge; MBR: membrane bioreactor; DHS reactor: down-flow hanging sponge (DHS) reactor

Table 7. Viral concentrations in tertiary effluents worldwide

\begin{tabular}{|c|c|c|c|c|c|}
\hline Area & Viral Pathogen & $\begin{array}{l}\text { Percent Positive } \\
\text { (\# of samples) }\end{array}$ & $\begin{array}{c}\text { Mean concentration } \\
\text { (GC/L) }\end{array}$ & Treatment type & Reference \\
\hline \multirow{3}{*}{ Brasil } & Adenovirus & $\begin{array}{l}50 \% \\
(3 / 6)\end{array}$ & $2.88 \mathrm{E}+03$ & $\mathrm{Cl} 2$ & \multirow{3}{*}{$\begin{array}{l}\text { Prado et } \\
\text { al., } 2011\end{array}$} \\
\hline & Hepatitis A & $\begin{array}{c}100 \% \\
(4 / 4)\end{array}$ & $2.8 \mathrm{E}+04$ & $\mathrm{Cl} 2$ & \\
\hline & Rotavirus & $\begin{array}{l}66 \% \\
(3 / 4)\end{array}$ & $1.20 \mathrm{E}+05$ & $\mathrm{Cl} 2$ & \\
\hline \multirow{5}{*}{ Canada } & Adenovirus & $\begin{array}{c}100 \% \\
(16 / 16)\end{array}$ & $8.71 \mathrm{E}+04$ & UV & \multirow{5}{*}{$\begin{array}{c}\text { Qiu et al., } \\
2015\end{array}$} \\
\hline & Adenovirus & $\begin{array}{c}6 \% \\
(1 / 16)\end{array}$ & $1.86 \mathrm{E}+04$ & $\mathrm{UF}$ and $\mathrm{Cl} 2$ & \\
\hline & Astrovirus & $\begin{array}{c}6 \% \\
(1 / 16)\end{array}$ & $3.54 \mathrm{E}+03$ & $\mathrm{UF}$ and $\mathrm{Cl} 2$ & \\
\hline & Rotavirus & $\begin{array}{c}38 \% \\
(6 / 16)\end{array}$ & $7.94 \mathrm{E}+02$ & $\mathrm{UF}$ and $\mathrm{Cl} 2$ & \\
\hline & Enterovirus & $\begin{array}{c}6 \% \\
(1 / 16)\end{array}$ & $7.41 \mathrm{E}+02$ & $\mathrm{UF}$ and $\mathrm{Cl} 2$ & \\
\hline \multirow{2}{*}{ Germany } & Enterovirus & $\begin{array}{c}8 \% \\
(1 / 13)\end{array}$ & $6.0 \mathrm{E}+03$ & UV & \multirow{2}{*}{$\begin{array}{l}\text { Leifels et } \\
\text { al., } 2016\end{array}$} \\
\hline & Rotavirus & $\begin{array}{c}0 \% \\
(0 / 13)\end{array}$ & Non detected & UV & \\
\hline \multirow{4}{*}{ Spain } & Adenovirus & $\begin{array}{c}72 \% \\
(16 / 22)\end{array}$ & $1.9 \mathrm{E}+03$ & Actiflo ${ }^{\circledR}$ and UV & \multirow{4}{*}{$\begin{array}{l}\text { Rusiñol et } \\
\text { al., } 2015\end{array}$} \\
\hline & Hepatitis E & $\begin{array}{c}0 \% \\
(0 / 22)\end{array}$ & Non detected & Actiflo ${ }^{\circledR}$ and UV & \\
\hline & Norovirus GGII & $\begin{array}{c}54 \% \\
(12 / 22)\end{array}$ & $3.09 E+05$ & Actiflo ${ }^{\circledR}$ and UV & \\
\hline & Polyomavirus & $\begin{array}{c}21 \% \\
(5 / 22)\end{array}$ & $4.67 \mathrm{E}+02$ & Actiflo ${ }^{\circledR}$ and UV & \\
\hline
\end{tabular}




\begin{tabular}{|c|c|c|c|c|c|}
\hline Area & Viral Pathogen & $\begin{array}{l}\text { Percent Positive } \\
\text { (\# of samples) }\end{array}$ & $\begin{array}{c}\text { Mean concentration } \\
(\mathrm{GC} / \mathrm{L})\end{array}$ & Treatment type & Reference \\
\hline \multirow{3}{*}{ USA } & Adenovirus & $\begin{array}{c}13 \% \\
(3 / 23)\end{array}$ & $1.0 \mathrm{E}+01$ & $\mathrm{UV}$ and $\mathrm{Cl} 2$ & \multirow{3}{*}{$\begin{array}{l}\text { Francy et } \\
\text { al., } 2012\end{array}$} \\
\hline & Enterovirus & $\begin{array}{c}0 \% \\
(0 / 23)\end{array}$ & Non detected & UV and $\mathrm{Cl} 2$ & \\
\hline & Norovirus GGI & $\begin{array}{c}8 \% \\
(2 / 23)\end{array}$ & $1.0 \mathrm{E}+01$ & UV and $\mathrm{Cl} 2$ & \\
\hline
\end{tabular}

UV: Ultraviolet, UF: Ultrafiltration, $\mathrm{Cl}_{2}$ : Chlorination 


\section{References}

Altzibar, J.M., Zigorraga, C., Rodriguez, R., Leturia, N., Garmendia, A., Rodriguez, A. et al. (2015). Outbreak of acute gastroenteritis caused by contamination of drinking water in a factory, the Basque Country. Journal of Water and Health. 13, pp. 168. doi: 10.2166/wh.2014.048.

Arankalle, V., Sarada Devi, K.L., Lole, K.S., Shenoy, K.T., Verma, V. and Haneephabi, M. (2006). Molecular characterization of hepatitis A virus from a large outbreak from Kerala, India. The Indian Journal of Medical Research. 123, pp. 760-769.

Atmar, R.L., Opekun, A.R., Gilger, M.A., Estes, M.K., Crawford, S.E., Neill, F.H. et al. (2008). Norwalk virus shedding after experimental human infection. Emerging Infectious Diseases. 14, pp. 1553-1557. doi: 10.3201/eid1410.080117.

Aw, T.G. and Gin, K.Y. (2010). Environmental surveillance and molecular characterization of human enteric viruses in tropical urban wastewaters. Journal of Applied Microbiology. 109, pp. 716-730.

Blinkova, O., Rosario, K., Li, L., Kapoor, A., Slikas, B., Bernardin, F. et al. (2009). Frequent detection of highly diverse variants of cardiovirus, cosavirus, bocavirus, and circovirus in sewage samples collected in the United States. Journal of Clinical Microbiology. 47, pp. 3507-13. doi: 10.1128/JCM.01062-09.

Bofill-Mas, S. and Girones, R. (2001). Excretion and transmission of JCV in human populations. Journal of Neurovirology. 7, pp. 345-349. doi: 10.1080/13550280152537210.

Bosch, A. and Guix, S.P.R. (2013). Epidemiology of human astrovirus. Astrovirus Research: Essential Ideas, Everyday Impacts, Future Directions. (Schultz-Cherry, S., ed.). Springer. New York, NY. pp. 1-18.

Bosch, A., Pintó, R.M. and Guix, S. (2014). Human astroviruses. Clinical Microbiology Reviews. 27, pp. 1048-1074. doi: 10.1128/CMR.00013-14.

Bouquet, J., Tessé, S., Lunazzi, A., Eloit, M., Rose, N., Nicand, E. et al. (2011). Close similarity between sequences of hepatitis e virus recovered from humans and swine, France, 2008-2009. Emerging Infectious Diseases. 17, pp. 2018-2025. doi: 10.3201/eid1711.110616.

Bouquet, J., Cheval, J., Rogee, S., Pavio, N. and Eloit, M. (2012). Identical Consensus Sequence and Conserved Genomic Polymorphism of Hepatitis E Virus during Controlled Interspecies Transmission. Journal of Virology. 86, pp. 6238-6245. doi: 10.1128/JVI.06843-11.

Bozkurt, D., Selimoğlu, M.A., Otlu, B. and Sandıkkaya, A. (2015). Eight different viral agents in childhood acute gastroenteritis. The Turkish Journal of Pediatrics. 57, pp. 68-73.

Braeye, T., De Schrijver, K., Wollants, E., Van Ranst, M. and Verhaegen, J. (2015). A large community outbreak of gastroenteritis associated with consumption of drinking water contaminated by river water, Belgium, 2010. Epidemiology and Infection. 143, pp. 711-719.

Caballero, S., Guix, S., El-Senousy, W.M., Calicó, I., Pinto, R.M. and Bosch, A. (2003). Persistent gastroenteritis in children infected with astrovirus: Association with serotype-3 strains. Journal of Medical Virology. 71, pp. 245-250. doi: 
10.1002/jmv.10476.

Cantalupo, P.G., Calgua, B., Zhao, G., Hundesa, A., Wier, A.D., Katz, J.P. et al. (2011). Raw sewage harbors diverse viral populations. mBio. 2, doi: 10.1128/mBio.00180-11.

Chandra, N.S., Sharma, A., Malhotra, B. and Rai, R.R. (2010). Dynamics of HEV viremia, fecal shedding and its relationship with transaminases and antibody response in patients with sporadic acute hepatitis E. Virology Journal. 7(1), pp. 213.

Cook, N., D'Agostino, M. and Johne, R. (2017). Potential Approaches to Assess the Infectivity of Hepatitis E Virus in Pork Products: A Review. Food and Environmental Virology. Springer US. doi: 10.1007/s12560-017-9303-7.

Craun, G.F., Brunkard, J.M., Yoder, J.S., Roberts, V.A., Carpenter, J., Wade, T. et al. (2010). Causes of outbreaks associated with drinking water in the United States from 1971 to 2006. Clinical Microbiology Reviews. 23, pp. 507-528.

de Graaf, M., van Beek, J. and Koopmans, M.P.G. (2016). Human norovirus transmission and evolution in a changing world. Nature Reviews Microbiology. 14, pp. 421-433. doi: 10.1038/nrmicro.2016.48.

Desselberger, U. and Gray, J. (1995). Principles and practice of clinical virology. FEBS Letters. 392, (Zuckerman, A.J., J.E., B. and Pattison, J.R., ed.). Wiley and Sons, Chichester. pp. 766. doi: 10.1016/0014-5793(96)89439-7.

Dey, S.K., Phathammavong, O., Nguyen, T.D., Thongprachum, A., Chan-it, W., Okitsu, S. et al. (2012). Seasonal pattern and genotype distribution of sapovirus infection in Japan, 2003-2009. Epidemiology and Infection. 140, pp. 74-77. doi: 10.1017/S0950268811000240.

Drexler, J.F., Baumgarte, S., Luna, L.K., Eschbach-Bludau, M., Lukashev, A.N. and Drosten, C. (2011). Aichi virus shedding in high concentrations in patients with acute diarrhea. Emerging Infectious Diseases. 17, pp. 1544-1547. doi: 10.3201/eid1708.101556.

EFSA (2012). Trends and Sources of Zoonoses, Zoonotic Agents and Food-borne Outbreaks in 2010. Reports of the European Food Safety Authority. 10, pp. 1-442. doi: 10.2903/j.efsa.2012.2597.

Eftim, S.E., Hong, T., Soller, J., Boehm, A., Warren, I., Ichida, A. et al. (2017). Occurrence of norovirus in raw sewage - A systematic literature review and meta-analysis. Water Research. 111, pp. 366-374. doi: 10.1016/j.watres.2017.01.017.

ENHIS (2009). Outbreaks of waterborne diseases. fact sheet 1.1. World Health Organization Europe. World Health Organization. pp. 1-6.

Estes, M.K., Palmer, E.L. and Obijeski, J.F. (1983). Rotaviruses: A Review. Current Topics in Microbiology and Immunology. (Cooper, M., Hofschneider, P.H., Koprowski, H., Melchers, F., Rott, R., Schweiger, H.G. et al., ed.). Springer Berlin Heidelberg. Berlin, Heidelberg. pp. 123-184. doi: 10.1007/978-3-642-69159-1_3.

Fares, A. (2015). Seasonality of hepatitis: A review update. Journal of Family Medicine and Primary Care. 4, pp. 96. doi: 10.4103/2249-4863.152263.

Francy, D.S., Stelzer, E.A., Bushon, R.N., Brady, A.M., Williston, A.G., Riddell, K.R. et al. (2012). Comparative effectiveness 
of membrane bioreactors, conventional secondary treatment, and chlorine and UV disinfection to remove microorganisms from municipal wastewaters. Water Research. 46, pp. 4164-78.

Fratini, M., Di Bonito, P. and La Rosa, G. (2014). Oncogenic Papillomavirus and Polyomavirus in Water Environments: Is There a Potential for Waterborne Transmission?. Food and Environmental Virology. 6, pp. 1-12. doi: 10.1007/s12560-013-9134-0.

Fumian, T., Guimarães, F., Pereira Vaz, B., da Silva, M.T., Muylaert, F., Bofill-Mas, S. et al. (2010). Molecular detection, quantification and characterization of human polyomavirus JC from waste water in Rio De Janeiro, Brazil. Journal of Water and Health. 8, pp. 438-445. doi: 10.2166/wh.2010.090.

Gould, H.L., Walsh, K.A., Vieira, A.R., Herman, K., Williams, I.T., Hall, A.J. et al. (2013). Surveillance for foodborne disease outbreaks - United States, 1998-2008. Morbidity and Mortality Weekly Report. Surveillance Summaries (Washington, D.C. : 2002). 62, pp. 1-34.

Hamza, I.A., Jurzik, L., Wilhelm, M. and Uberla, K. (2009). Detection and quantification of human bocavirus in river water. Journal of General Virology. 90, pp. 2634-2637. doi: 10.1099/vir.0.013557-0.

Haramoto, E. and Kitajima, M. (2017). Quantification and Genotyping of Aichi Virus 1 in Water Samples in the Kathmandu Valley, Nepal. Food and Environmental Virology. pp. 1-4. doi: 10.1007/s12560-017-9283-7.

Haramoto, E., Katayama, H., Phanuwan, C. and Ohgaki, S. (2008). Quantitative detection of sapoviruses in wastewater and river water in Japan. Letters in Applied Microbiology. 46, pp. 408-413. doi: 10.1111/j.1472-765X.2008.02330.x.

Hellmer, M., Paxeus, N., Magnius, L., Enache, L., Arnholm, B., Johansson, A. et al. (2014). Detection of pathogenic viruses in sewage provided early warnings of hepatitis A virus and norovirus outbreaks. Applied and Environmental Microbiology. 80, pp. 6771-81.

Hewitt, J., Leonard, M., Greening, G.E. and Lewis, G.D. (2011). Influence of wastewater treatment process and the population size on human virus profiles in wastewater. Water Research. 45, pp. 6267-76.

Iaconelli, M., Divizia, M., Della Libera, S., Di Bonito, P. and La Rosa, G. (2016). Frequent Detection and Genetic Diversity of Human Bocavirus in Urban Sewage Samples. Food and Environmental Virology. 8, pp. 289-295. doi: 10.1007/s12560-016-9251-7.

Iaconelli, M., Purpari, G., Libera, S.D., Petricca, S., Guercio, A., Ciccaglione, A.R. et al. (2015). Hepatitis A and E Viruses in Wastewaters, in River Waters, and in Bivalve Molluscs in Italy. Food and Environmental Virology. 7, pp. 316-324.

Inoue, J., Ueno, Y., Nagasaki, F., Akahane, T., Fukushima, K., Kogure, T. et al. (2009). Sporadic acute hepatitis E occurred constantly during the last decade in northeast Japan. Journal of Gastroenterology. 44, pp. 329-337. doi: 10.1007/s00535-009-0012-3.

Kaplan, J.E., Gary, G.W. and Baron, R.C. (1982). Epidemiology of Norwalk gastro- enteritis and the role of Norwalk virus in outbreaks of acute nonbacterial gastroenteritis. Annals of Internal Medicine. 96, pp. 756-761. doi: 20557901.

Kapusinszky, B., Minor, P. and Delwart, E. (2012). Nearly Constant Shedding of Diverse Enteric Viruses by Two Healthy 
Infants. Journal of Clinical Microbiology. 50, pp. 3427-3434. doi: 10.1128/JCM.01589-12.

Katayama, H., Haramoto, E., Oguma, K., Yamashita, H., Tajima, A., Nakajima, H. et al. (2008). One-year monthly quantitative survey of noroviruses, enteroviruses, and adenoviruses in wastewater collected from six plants in Japan. Water Research. 42, pp. 1441-1448. doi: 10.1016/j.watres.2007.10.029.

Kauppinen, A., Pitkänen, T. and Miettinen, I.T. (2017). Persistent Norovirus Contamination of Groundwater Supplies in Two Waterborne Outbreaks. Food and Environmental Virology. 1-12, doi: 10.1007/s12560-017-9320-6.

Khan, S.U., Atanasova, K.R., Krueger, W.S., Ramirez, A. and Gray, G.C. (2013). Epidemiology, geographical distribution, and economic consequences of swine zoonoses: a narrative review. Emerging Microbes and Infections. 2, pp. e92. doi: 10.1038/emi.2013.87.

Khetsuriani, N., Helfand, R., Pallansch, M., Kew, O., Fowlkes, A., Oberste, S. et al. (2009). Limited duration of vaccine poliovirus and other enterovirus excretion among human immunodeficiency virus infected children in Kenya. BMC Infectious Diseases. 9, pp. 136. doi: 10.1186/1471-2334-9-136.

Kim, J.H., Nelson, K.E., Panzner, U., Kasture, Y., Labrique, A.B. and Wierzba, T.F. (2014). A systematic review of the epidemiology of hepatitis E virus in Africa. BMC Infectious Diseases. 14, pp. 308. doi: 10.1186/1471-2334-14-308.

Kitajima, M. and Gerba, C. (2015). Aichi Virus 1: Environmental Occurrence and Behavior. Pathogens. 4, pp. 256-268. doi: 10.3390/pathogens4020256.

Kling, C.L., Wright, A.T., Katz, S.E., Mcclure, G.B., Gardner, J.S., Williams, J.T. et al. (2012). Dynamics of urinary polyomavirus shedding in healthy adult women. Journal of Medical Virology. 84, pp. 1459-1463. doi: 10.1002/jmv.23319.

Kobayashi, N., Oshiki, M., Ito, T., Segawa, T., Hatamoto, M., Kato, T. et al. (2017). Removal of human pathogenic viruses in a down-flow hanging sponge (DHS) reactor treating municipal wastewater and health risks associated with utilization of the effluent for agricultural irrigation. Water Research. 110, pp. 389-398.

Kotwal, G. and Cannon, J.L. (2014). Environmental persistence and transfer of enteric viruses. Current Opinion in Virology. 4, pp. 37-43. doi: 10.1016/j.coviro.2013.12.003.

Laassri, M., Lottenbach, K., Belshe, R., Wolff, M., Rennels, M., Plotkin, S. et al. (2005). Effect of Different Vaccination Schedules on Excretion of Oral Poliovirus Vaccine Strains. The Journal of Infectious Diseases. 192, pp. 2092-2098. doi: $10.1086 / 498172$.

Lau, S.K.P., Yip, C.C.Y., Que, T., Lee, R.A., Au-Yeung, R.K.H., Zhou, B. et al. (2007). Clinical and Molecular Epidemiology of Human Bocavirus in Respiratory and Fecal Samples from Children in Hong Kong. The Journal of Infectious Diseases. 196, pp. 986-993. doi: 10.1086/521310.

Le Cann, P., Ranarijaona, S., Monpoeho, S., Le Guyader, F. and Ferré, V. (2004). Quantification of human astroviruses in sewage using real-time RT-PCR. Research in Microbiology. 155, pp. 11-15. doi: 10.1016/j.resmic.2003.09.013.

Lee, C.H., Kwon, O.S., Byun, K.S., Yeon, J.E., Park, S.H., Kim, J.S. et al. (2000). Detection of hepatitis A viral RNA in sera of patients with acute hepatitis A. Journal of Gastroenterology and Hepatology. 15, pp. 1043-7. 
Lee, R.M., Lessler, J., Lee, R.A., Rudolph, K.E., Reich, N.G., Perl, T.M. et al. (2013). Incubation periods of viral gastroenteritis: a systematic review. BMC Infectious Diseases. 13, pp. 446. doi: 10.1186/1471-2334-13-446.

Le Guyader, F.S., Le Saux, J.C., Ambert-Balay, K., Krol, J., Serais, O., Parnaudeau, S. et al. (2008). Aichi virus, norovirus, astrovirus, enterovirus, and rotavirus involved in clinical cases from a French oyster-related gastroenteritis outbreak. Journal of Clinical Microbiology. 46, pp. 4011-4017. doi: 10.1128/JCM.01044-08.

Leifels, M., Hamza, I.A., Krieger, M., Wilhelm, M., Mackowiak, M. and Jurzik, L. (2016). From lab to lake - Evaluation of current molecular methods for the detection of infectious enteric viruses in complex water matrices in an urban area. PLoS ONE. 11, pp. 1-16. doi: 10.1371/journal.pone.0167105.

Li, L., Kapoor, A., Slikas, B., Bamidele Soji, O., Wang, C., Shaukat, S. et al. (2010). Multiple diverse circoviruses infect farm animals and are commonly found in human and chimpanzee feces. Journal of Virology. 84, pp. 1674-82. doi: 10.1128/JVI.02109-09.

Lion, T., Kosulin, K., Landlinger, C., Rauch, M., Preuner, S., Jugovic, D. et al. (2010). Monitoring of adenovirus load in stool by real-time PCR permits early detection of impending invasive infection in patients after allogeneic stem cell transplantation. Leukemia. doi: 10.1038/leu.2010.4.

Masclaux, F.G., Hotz, P., Friedli, D., Savova-Bianchi, D. and Oppliger, A. (2013). High occurrence of hepatitis E virus in samples from wastewater treatment plants in Switzerland and comparison with other enteric viruses. Water Research. 47, pp. 5101-5109. doi: 10.1016/j.watres.2013.05.050.

Melnick, J. and Rennick, V. (1980). Infectivity titers of enterovirus as found in human stools. Journal of Medical Virology. 5, pp. 205-20. doi: 16167509.

Mena, K.D. and Gerba, C.P. (2009). Waterborne adenovirus. Reviews of Environmental Contamination and Toxicology. 198, pp. 133-67. doi: 10.1007/978-0-387-09647-6_4.

Meng, X.J. (2013). Zoonotic and foodborne transmission of hepatitis E virus. Seminars in Liver Disease. 33, pp. 41-9. doi: 10.1055/s-0033-1338113.

Myrmel, M., Lange, H. and Rimstad, E. (2015). A 1-Year Quantitative Survey of Noro-, Adeno-, Human Boca-, and Hepatitis E Viruses in Raw and Secondarily Treated Sewage from Two Plants in Norway. Food and Environmental Virology. 7(3), pp. 213-23.

Nordgren, J., Matussek, A., Mattsson, A., Svensson, L. and Lindgren, P.E. (2009). Prevalence of norovirus and factors influencing virus concentrations during one year in a full-scale wastewater treatment plant. Water Research. 43, pp. 1117-1125. doi: 10.1016/j.watres.2008.11.053.

Ouardani, I., Turki, S., Aouni, M. and Romalde, J.L. (2016). Detection and Molecular Characterization of Hepatitis A Virus from Tunisian Wastewater Treatment Plants with Different Secondary Treatments. Applied and Environmental Microbiology. 82, pp. 3834-3845. doi: 10.1128/AEM.00619-16.Editor.

Pérez-Sautu, U., Sano, D., Guix, S., Kasimir, G., Pinto, R.M. and Bosch, A. (2012). Human norovirus occurrence and 
diversity in the Llobregat river catchment, Spain. Environmental Microbiology. 14, pp. 494-502. doi: 10.1111/j.1462-2920.2011.02642.x.

Papp, H., László, B., Jakab, F., Ganesh, B., De Grazia, S., Matthijnssens, J. et al. (2013). Review of group A rotavirus strains reported in swine and cattle. Veterinary Microbiology. 165, pp. 190-199. doi: 10.1016/j.vetmic.2013.03.020.

Papp, H., Matthijnssens, J., Martella, V., Ciarlet, M. and Banyai, K. (2013). Global distribution of group A rotavirus strains in horses: A systematic review. Vaccine. 31, pp. 5627-5633. doi: 10.1016/j.vaccine.2013.08.045.

Phan Gia, T., Mori, D., Deng, X., Rajindrajith, S., Ranawaka, U., Fan Ng, T.F. et al. (2015). Small circular single stranded DNA viral genomes in unexplained cases of human encephalitis, diarrhea, and in untreated sewage. Virology. 482, pp. 98-104. doi: 10.1016/j.virol.2015.03.011.

Polo, C., Pérez, J.L., Mielnichuck, A., Fedele, C.G., Niubò, J. and Tenorio, A. (2004). Prevalence and patterns of polyomavirus urinary excretion in immunocompetent adults and children. European Society of Clinical Infectious Diseases. 10, pp. 640-644. doi: 10.1111/j.1469-0691.2004.00882.x.

Prado, T., Silva, D.M., Guilayn, W.C., Rose, T.L., Gaspar, A.M. and Miagostovich, M.P. (2011). Quantification and molecular characterization of enteric viruses detected in effluents from two hospital wastewater treatment plants. Water Research. 45, pp. 1287-97.

Prado, T., Silva, D.M., Guilayn, W.C., Rose, T.L., Gaspar, A.M. and Miagostovich, M.P. (2011). Quantification and molecular characterization of enteric viruses detected in effluents from two hospital wastewater treatment plants. Water Research. 45, pp. 1287-1297. doi: 10.1016/j.watres.2010.10.012.

Prevost, B., Lucas, F.S., Goncalves, A., Richard, F., Moulin, L. and Wurtzer, S. (2015). Large scale survey of enteric viruses in river and waste water underlines the health status of the local population. Environment International. 79, pp. 42-50.

Price-Hayward, M. and Hartnell, R. (2016). Summary Report of Joint Scientific Workshop on Foodborne Viruses. EFSA Supporting Publications. 13, doi: 10.2903/sp.efsa.2016.EN-1103.

Proenca-Modena, J.L., Martinez, M., Amarilla, A.A., Espínola, E.E., Galeano, M.E., Fariña, N. et al. (2013). Viral load of human bocavirus-1 in stools from children with viral diarrhoea in Paraguay. Epidemiology and Infection. 141, pp. 2576-2580. doi: 10.1017/S095026881300023X.

Purnell, S., Ebdon, J., Buck, A., Tupper, M. and Taylor, H. (2016). Removal of phages and viral pathogens in a full-scale MBR: Implications for wastewater reuse and potable water. Water Research. 100, pp. 20-27. doi: 10.1016/j.watres.2016.05.013.

Qiu, Y., Lee, B.E., Newmann, N., Ashbolt, N., Craik, S., Maal-Bared, R. et al. (2015). Assessment of human virus removal during municipal wastewater treatment in Edmonton, Canada. Journal of Applied Microbiology. 119, pp. 1729-1739.

Rachmadi, A.T., Kitajima, M., Pepper, I.L. and Gerba, C.P. (2016). Enteric and indicator virus removal by surface flow wetlands. The Science of the Total Environment. 542, pp. 976-82.

Ramani, S., Atmar, R. and Estes, M.K. (2014). Epidemiology of human noroviruses and updates on vaccine development. 
Current Opinion Gastroenterology. 30, pp. 25-33. doi: 10.1038/jid.2014.371.

Ricci, A., Allende, A., Bolton, D., Chemaly, M., Davies, R., Fernandez-Escamez, P.S. et al. (2017). Public health risks associated with hepatitis E virus (HEV) as a food-borne pathogen. EFSA Journal. 15, doi: 10.2903/j.efsa.2017.4886.

Richardson, S., Grimwood, K., Gorrell, R., Palombo, E., Barnes, G. and Bishop, R. (1998). Extended excretion of rotavirus after severe diarrhoea in young children. Lancet. 351, pp. 1844-1848. doi: 10.1016/S0140-6736(97)11257-0.

Rimoldi, S.G., Stefani, F., Pagani, C., Chenal, L.L., Zanchetta, N., Di Bartolo, I. et al. (2011). Epidemiological and clinical characteristics of pediatric gastroenteritis associated with new viral agents. Archives of Virology. 156, pp. 1583-1589. doi: 10.1007/s00705-011-1037-5.

Rockx, B., de Wit, M., Vennema, H., Vinjé, J., de Bruin, E., van Duynhoven, Y. et al. (2002). Natural history of human calicivirus infection: a prospective cohort study. Clinical Infectious Diseases. 35, pp. 246-53. doi: 10.1086/341408.

Rusiñol, M., Fernandez-Cassi, X., Timoneda, N., Carratala, A., Abril, J.F., Silvera, C. et al. (2015). Evidence of viral dissemination and seasonality in a Mediterranean river catchment: Implications for water pollution management. Journal of Environmental Management. 159, doi: 10.1016/j.jenvman.2015.05.019.

Schildgen, O., Müller, A., Allander, T., Mackay, I.M., Völz, S., Kupfer, B. et al. (2008). Human bocavirus: Passenger or pathogen in acute respiratory tract infections?. Clinical Microbiology Reviews. 21, pp. 291-304. doi: 10.1128/CMR.00030-07.

Schmitz, B.W., Kitajima, M., Campillo, M.E., Gerba, C.P. and Pepper, I.L. (2016). Virus reduction during advanced bardenpho and conventional wastewater treatment processes. Environmental Science and Technology. 50, pp. 9524-9532. doi: 10.1021/acs.est.6b01384.

Sedmak, G., Bina, D., MacDonald, J. and Couillard, L. (2005). The occurrence of culturable viruses in source water for two drinking water treatment plants and the influent and effluent of a wastewater treatment plant in Milwaukee. Applied and Environmental Microbiology. 71, pp. 1042-1050. doi: 10.1128/AEM.71.2.1042.

Sridhar, S., Teng, J.L.L., Chiu, T.Ho, Lau, S.K.P. and Woo, P.C.Y. (2017). Hepatitis E virus genotypes and evolution: Emergence of camel hepatitis E variants. International Journal of Molecular Sciences. 18, doi: 10.3390/ijms18040869.

Symonds, E.M., Verbyla, M.E., Lukasik, J.O., Kafle, R.C., Breitbart, M. and Mihelcic, J.R. (2014). A case study of enteric virus removal and insights into the associated risk of water reuse for two wastewater treatment pond systems in Bolivia. Water Research. 65, pp. 257-270. doi: 10.1016/j.watres.2014.07.032.

Takahashi, M., Tanaka, T., Azuma, M., Kusano, E., Aikawa, T., Shibayama, T. et al. (2007). Prolonged fecal shedding of hepatitis E virus (HEV) during sporadic acute hepatitis E: Evaluation of infectivity of HEV in fecal specimens in a cell culture system. Journal of Clinical Microbiology. 45, pp. 3671-3679. doi: 10.1128/JCM.01086-07.

Torner, N., Martinez, A., Broner, S., Moreno, A., Camps, N. and Domínguez, A. (2016). Epidemiology of acute gastroenteritis outbreaks caused by human calicivirus (Norovirus and Sapovirus) in Catalonia: A two year prospective study, 2010-2011. PLoS ONE. 11, pp. 2010-2011. doi: 10.1371/journal.pone.0152503. 
Väisänen, E., Kuisma, I., Phan, T.G., Delwart, E., Lappalainen, M., Tarkka, E. et al. (2014). Bufavirus in Feces of Patients with Gastroenteritis, Finland. Emerging Infectious Diseases. 20, pp. 1077-1079. doi: 10.3201/eid2006.131674.

Van Tan, L., van Doorn, H.R., Nghia, H.D.T., Chau, T.T.H., Tu, L.T.P., de Vries, M. et al. (2013). Identification of a new cyclovirus in cerebrospinal fluid of patients with acute central nervous system infections. mBio. 4, pp. e00231-13. doi: 10.1128/mBio.00231-13.

Vetter, M.R., Staggemeier, R., Vecchia, A.D., Henzel, A., Rigotto, C. and Spilki, F.R. (2015). Seasonal variation on the presence of adenoviruses in stools from non-diarrheic patients. Brazilian Journal of Microbiology. 46, pp. 749-752. doi: 10.1590/S1517-838246320140718.

Victoria, M., Tort, L.F., García, M., Lizasoain, A., Maya, L., Leite, J.P. et al. (2014). Assessment of gastroenteric viruses from wastewater directly discharged into Uruguay River, Uruguay. Food and Environmental Virology. 6, pp. 116-124. doi: 10.1007/s12560-014-9143-7.

Villar, L.M., De Paula, V.S., Diniz-Mendes, L., Guimaraes, F.R., Ferreira, F.F.M., Shubo, T.C. et al. (2007). Molecular detection of hepatitis A virus in urban sewage in Rio de Janeiro, Brazil. Letters in Applied Microbiology. 45, pp. 168-173. doi: 10.1111/j.1472-765X.2007.02164.x.

Yoder, J.S., Hlavsa, M.C., Craun, G.F., Hill, V., Roberts, V., Yu, P.A. et al. (2011). Surveillance for waterborne disease and outbreaks associated with recreational water use and other aquatic facility-associated health events - United States, 2007-2008. Morbidity and Mortality Weekly Report. 60, pp. 1-38. doi: ss6012a4 [pii].

Zhang, L., Yan, B. and Xu, A. (2016). A hepatitis E outbreak by genotype 4 virus in Shandong province, China. Vaccine. 34, pp. 3715-3718. doi: 10.1016/j.vaccine.2016.06.010. 